\title{
The Crystal and Molecular Structures of trans Square-planar Complexes of Tellurium Diselenocyanate with Trimethyl- enethiourea and Tetramethylthiourea
}

\author{
KJELL A SE, OLAV FOSS and INGVALD ROTI \\ Chemical Institute, University of Bergen, N-5000 Bergen, Norway
}

\begin{abstract}
The crystal and molecular structures of trans-diselenocyanatobis(trimethylenethiourea)tellurium(II), $\mathrm{Te}\left(\mathrm{S}: \mathrm{C} \cdot \mathrm{NH} \cdot\left[\mathrm{CH}_{\mathbf{8}}\right]_{\mathbf{8}} \cdot \mathrm{NH}\right)_{\mathbf{g}}(\mathrm{SeCN})_{\mathbf{2}}$ (I), and trans-diselenocyanatobis(tetramethylthiourea)tellurium(II), $\mathrm{Te}\left(\mathrm{SC}\left[\mathrm{N}\left(\mathrm{CH}_{3}\right)_{2}\right]_{2}\right)_{2}(\mathrm{SeCN})_{2}(\mathrm{II})$, have been determined by X-ray diffraction methods. Both complexes crystallize in space group $P 2_{1} / c$ (No. 14) with $Z=2$, and with the tellurium atoms located in centres of symmetry. Cell dimensions and densities are: $a=4.782(3) \AA$, $b=15.362(5) \quad \AA, c=13.203(5) \quad \AA, \beta=106.54(5)^{\circ}, \varrho_{o}($ flotation $)=2.05$ $\mathrm{g} / \mathrm{cm}^{3}, \varrho_{c}=2.04 \mathrm{~g} / \mathrm{cm}^{3}$ for $\mathrm{I}$, and $a=8.804(5) \AA, b=6.363(6) \AA, c=$ $19.749(8) \AA, \beta=98.80(5)^{\circ}, \varrho_{o}($ flotation $)=1.86 \mathrm{~g} / \mathrm{cm}^{3}, \varrho_{c}=1.83 \mathrm{~g} / \mathrm{cm}^{3}$ for II. Intensity data were collected using integrating Weissenberg techniques. Based on 924 independent, non-zero reflections for 1 , and 1119 for II, refinement by full-matrix, least squares methods resulted in conventional $R$-values of 0.073 and 0.076 , respectively.

In both complexes the tellurium atom is bonded to two selenium atoms and two sulphur atoms in a trans square-planar arrangement, with the dimensions: $\mathrm{Te}-\mathrm{Se}=2.834(2) \AA$, $\mathrm{Te}-\mathrm{S}=2.670$ (5) $\AA, \angle \mathrm{Se}-\mathrm{Te}-\mathrm{S}=89.73(11)^{\circ}$ in $\mathrm{I}$; and $\mathrm{Te}-\mathrm{Se}=2.815(3) \AA$, $\mathrm{Te}-\mathrm{S}=2.728(4) \AA, \angle \mathrm{Se}-\mathrm{T} \theta-\mathrm{S}=91.61(10)^{\circ}$ in II.
\end{abstract}

The crystal structure of a centrosymmetric, trans square-planar complex 1 of tellurium diselenocyanate with ethylenethiourea, $\mathrm{Te}(\mathrm{etu})_{2}(\mathrm{SeCN})_{2}$, has been determined. ${ }^{1}$ This article reports the crystal structures of two additional tellurium diselenocyanate complexes, $\mathrm{Te}(\mathrm{trtu})_{2}(\mathrm{SeCN})_{2}$ and $\mathrm{Te}(\mathrm{tmtu})_{2}\left(\mathrm{SeCN}_{2}\right)$, where $\operatorname{tr} t u=$ trimethylenethiourea and tmtu=tetramethylthiourea. As in the ethylenethiourea complex, the tellurium atoms in both compounds lie in crystallographic centres of symmetry, and the configuration around tellurium is square-planar trans.

\section{EXPERIMENTAL}

trans-Diselenocyanatobis(trimethylenethiourea)tellurium(II), $\mathrm{Te}(\mathrm{trtu})_{2}(\mathrm{SeCN})_{2}(\mathrm{I})$, and trans-diselenocyanatobis(tetramethylthiourea)tellurium(II), $\mathrm{Te}(\mathrm{tmtu})_{2}(\mathrm{SeCN})_{2}$ (II), were prepared from the dibromo complexes, $\mathrm{Te}(\mathrm{trtu})_{2} \mathrm{Br}_{2}{ }^{2}$ and $\mathrm{Te}(\mathrm{tmtu})_{2} \mathrm{Br}_{2}{ }^{3}$ and an 
excess of potassium selenocyanate in methanol. ${ }^{4}$ Crystallization from the gently warmed and filtered reaction mixtures took place on cooling. The crystals are light brown in colour, and are stable when dry, but liberate tellurium in contact with water as do other tellurium(II) complexes.

For determination of cell dimensions, $2 \theta$-values were measured from zero-layer Weissenberg photographs around the $a$ and $b$ axes, taken with CuK $\alpha_{1}$ radiation $(\lambda=1.5405 \AA)$. Sodium chloride powder lines were superimposed on the films for reference $(a=\mathbf{5 . 6 3 9 4}$ $\AA$ at $\left.18^{\circ} \mathrm{C}\right) .{ }^{5}$

Intensity data were collected using multiple-film, integrating, equi-inclination Weissenberg techniques with ( $\mathrm{Ni}$ - filtered) $\mathrm{CuK \alpha}$ radiation. The crystal dimensions of I, given as distances from a common origin to faces, had the following values for the crystal rotating about the $a$ axis (zero layer): distances to $(100)$ and $(\overline{100})=0.054 \mathrm{~mm}$, to $(011),(0 \overline{1}),(0 \overline{1} 1)$, and $(01 \overline{1})=0.023 \mathrm{~mm}$. The crystal rotating about the $a$ axis (upper layers) had the dimensions: distances to $(100)$ and $(\overline{1} 00)=0.088 \mathrm{~mm}$, to $(011),(0 \overline{1}),(0 \overline{1} 1)$, and $(0 \overline{1})=0.025 \mathrm{~mm}$. The dimensions of the erystal rotating about the $b$ axis were: distances to $(100)$ and $(\overline{1} 00)=0.042 \mathrm{~mm}$, to $(011),(0 \overline{1}),(0 \overline{1})$, and $(01 \overline{1})=0.032 \mathrm{~mm}$. The crystal of II rotating about the $a$ axis had the dimensions: distances to (001) and $(00 \overline{1})=0.054 \mathrm{~mm}$, to $(101)$ and $(\overline{1} 0 \overline{1})=0.066 \mathrm{~mm}$, to $(10 \overline{1})$ and $(\overline{1} 01)=0.089 \mathrm{~mm}$, to $(010)$ and $(0 \overline{1} 0)=0.044 \mathrm{~mm}$. The dimensions of the crystal rotating about the $b$ axis were: distances to $(100)$ and $(\overline{1} 00)=0.034 \mathrm{~mm}$, to $(001)$ and $(00 \overline{1})=0.026 \mathrm{~mm}$, to $(010)$ and $(0 \overline{\mathrm{I}} 0)=0.087 \mathrm{~mm}$.

Intensities of the $0 k l-2 k l$ and $h 0 l$ reflections of $I$, and the $0 k l, 1 k l$, and $h 0 l-h 3 l$ reflections of II, were estimated visually by comparison with a scale of timed exposures. Out of 1174 accessible, independent reflections for I, and 1638 for II, 924 and 1119, respectively, were strong enough to be measured. The remaining reflections were assigned an intensity equal to the observable limit, and labelled as unobserved reflections.

The intensities were corrected for absorption, using a modified version of the absorption correction method described by Busing and Levy. ${ }^{6}$ The corrections were based on the crystal dimensions quoted above, $8 \times 8 \times 8$ grids for all of the crystals, and $\mu=205$ $\mathrm{cm}^{-1}$ for I and $175 \mathrm{~cm}^{-1}$ for II. Lorentz and polarization corrections were carried out, and the corrected intensities were reduced to relative observed structure factors. No extinction corrections were applied.

Calculated structure factors were based on the atomic scattering factor curves listed in International Tables (Ref. 5, p. 202). Using Cromer's values of $\Delta f^{\prime}$ and $\Delta f^{\prime \prime},{ }^{7}$ the tellurium, selenium, and sulphur scattering curves were corrected for anomalous dispersion, by taking the amplitude of $f$ as the corrected value.

The structures were refined by a least squares, full-matrix program minimizing the function

$$
r=\sum W\left(\left|F_{\mathrm{o}}\right|-K\left|F_{\mathrm{c}}\right|\right)^{2}
$$

where $K$ is a scale factor. The weight, $W$, is defined by $W=1 /\left[\left(K a_{1}\right)^{2}+\sigma^{2}\left(F_{0}\right)\right]$, where $a_{1}$ is a constant and $\sigma\left(F_{0}\right)$ is the estimated standard deviation of $F_{0}$. Non-observed reflections for which $K \mid F_{\mathrm{c}} \mathrm{c}$ is greater than the observable limit, are included in the refinement with $\left|\boldsymbol{F}_{\mathrm{o}}\right|$ equal to the observable limit.

The calculations were carried out on an IBM 360/50 H computer, using a program library made available by the Weizmann Institute of Science, Rehovoth, Israel, and modified for use on the IBM computer by Dr. Dove Rabinovich. A program calculating weighted least squares planes was written by Mr. Knut Maartmann-Moe, of this Institute.

\section{CRYSTAL DATA}

The crystals of I occurred as monoclinic needles along $a$, bounded mainly by $\{011\}$. They exhibited a pronounced tendency of twinning. Using 28 high-angle $2 \theta$-values, the cell dimensions were calculated by a least squares procedure. The standard deviations, which do not include uncertainties in film radii, are given in parentheses:

Acta Chem. Scand. 25 (1971) No. 10 
$a=4.782(3) \AA, b=15.362(5) \AA, c=13.203(5) \AA, \beta=106.54(5)^{\circ}, V=929.8(8)$ $\AA^{3}, M=569.93, F(000)=540, Z=2, \varrho_{\circ}($ flotation $)=2.05 \mathrm{~g} / \mathrm{cm}^{3}, \varrho_{\mathrm{c}}=2.04 \mathrm{~g} / \mathrm{cm}^{3}$. The crystals of II occurred as monoclinic needles or prisms along $b$. Different batches of crystals showed varying forms. Cell dimensions, calculated as for I, were based on 65 high-angle $2 \theta$-values:

$a=8.804(5) \AA, b=6.363(6) \AA, c=19.749(8) \AA, \beta=98.80(5)^{\circ}, V=1093.3(13)$ $\AA^{3}, M=602.01, F^{\prime}(000)=580, Z=2, \varrho_{o}($ flotation $)=1.86 \mathrm{~g} / \mathrm{cm}^{3}, \varrho_{\mathrm{c}}=1.83 \mathrm{~g} / \mathrm{cm}^{3}$. For both compounds the systematic absences are $h 0 l$ when $l$ is odd, and $0 k 0$ when $k$ is odd. The uniquely determined space group is $P 2_{1} / c$ (No. 14).

\section{STRUCTURE DETERMINATION}

The structures were solved through Fourier syntheses in the $0 k l$ and $h 0 l$ projections. With the tellurium atoms in centres of symmetry, the initial phases were based on the tellurium contributions alone. As the tellurium atoms did not contribute to reflections with $k+l$ odd, the first Fourier maps in the $0 k l$ projections had extra (false) mirror planes. Two relatively high peaks, related by a false mirror plane, occurred in each map. The coordinates of one of the peaks were chosen as selenium coordinates. On inclusion of $k+l$ odd reflections in subsequent Fourier summations, the rest of the atoms, except hydrogen, could be located.

Three-dimensional least squares refinement with individual isotropic thermal parameters resulted in conventional $R$ values of 0.105 for $I$ and 0.094 for II. Some strong, low-order reflections seemed to have markedly lower observed than calculated structure factors; 29 such reflections of I, and 31 of II, were therefore given zero weight at this stage. After introduction of overall scale factors, and anisotropic thermal parameters for the tellurium, selenium, and sulphur atoms, the refinement was continued until no shift was greater than 0.19 times the standard deviation for I, and 0.16 times the standard deviation for II. The value of the adjustable constant $a_{1}$ in the weighting scheme was 3.4 for I and 1.3 for II during the last refinement cycles. The final values of $R$, including the reflections with zero weight mentioned above, and with non-observed reflections included when $K\left|F_{\mathrm{c}}\right|$ exceeded the observable limit, were 0.073 for I and 0.076 for II. The highest peaks in difference Fourier maps at this stage were $1.7 \mathrm{e} / \AA^{2}$ in the $0 k l$ projection of $\mathrm{I}$, and $1.3 \mathrm{e} / \AA^{2}$ in the $h 0 l$ projection of II.

The final atomic coordinates are listed in Table 1, together with isotropic thermal parameters for the carbon and nitrogen atoms, while Table 2 contains anisotropic thermal parameters for the heavier atoms. Observed and calculated structure factors are listed in Table 3 for I and Table 4 for II.

\section{RESULTS}

Bond lengths and angles are listed in Table 5 for the coordination groups, and in Table 6 for the ligands. The standard deviations are calculated from those of Table 1, without regard to coordinate covariances and standard deviations in cell dimensions. Drawings of the molecules are shown in Fig. 1 (trimethylenethiourea complex) and Fig. 2 (tetramethylthiourea complex). 
Table 1. Atomic coordinates in fractions of monoclinic cell edges. Origin at a centre of symmetry. Isotropic thermal parameters $\left(\AA^{2}\right)$ in the form $\exp \left[-8 \pi^{2} U\left(\sin ^{2} \theta / \lambda^{2}\right)\right]$. Standard deviations from the least squares refinement are given in parentheses.

Diselenocyanatobis(trimethylenethiourea)tellurium(II)

$\begin{array}{lllll} & x & y & z & U \\ \mathrm{Te} & 0 & 0 & 0 & \\ \mathrm{Se} & 0.4957(5) & 0.02231(11) & 0.17673(15) & \\ \mathrm{S} & 0.0846(13) & 0.15877(27) & -0.06807(34) & \\ \mathrm{N}(1) & 0.221(5) & 0.1004(12) & 0.3290(15) & 0.085(6) \\ \mathrm{N}(2) & -0.140(4) & 0.2058(8) & 0.0883(10) & 0.038(4) \\ \mathrm{N}(3) & -0.013(4) & 0.3139(9) & -0.0108(12) & 0.050(4) \\ \mathrm{C}(1) & 0.331(5) & 0.0695(11) & 0.2707(14) & 0.050(5) \\ \mathrm{C}(2) & -0.046(4) & 0.2312(9) & 0.0079(12) & 0.037(3) \\ \mathrm{C}(3) & -0.242(5) & 0.2649(11) & 0.1584(14) & 0.048(5) \\ \mathrm{C}(4) & -0.117(6) & 0.3521(16) & 0.1575(21) & 0.092(8) \\ \mathrm{C}(5) & -0.095(5) & 0.3850(14) & 0.0523(17) & 0.069(6)\end{array}$

Diselenocyanatobis(tetramethylthiourea)tellurium(II)

$\begin{array}{lcclc} & x & y & z & U \\ \text { Te } & 0 & 0 & 0 & \\ \text { Se } & -0.13897(21) & 0.37586(40) & 0.03414(10) & \\ \text { S } & 0.27479(38) & 0.11362(68) & 0.07433(18) & \\ \text { N(1) } & -0.2781(19) & 0.2197(30) & 0.1524(10) & 0.101(6) \\ \text { N(2) } & 0.2003(14) & -0.1763(26) & 0.1685(7) & 0.066(4) \\ \text { N(3) } & 0.4347(15) & -0.2205(24) & 0.1281(7) & 0.066(4) \\ \text { C(1) } & -0.2242(19) & 0.2864(32) & 0.1067(10) & 0.074(5) \\ \text { C(2) } & 0.3060(18) & -0.1079(30) & 0.1276(9) & 0.064(5) \\ \text { C(3) } & 0.0984(21) & -0.0304(33) & 0.1904(10) & 0.082(6) \\ \text { C(4) } & 0.1756(21) & -0.3927(40) & 0.1814(10) & 0.080(6) \\ \text { C(5) } & 0.5164(25) & -0.3516(40) & 0.1884(12) & 0.106(7) \\ \text { C(6) } & 0.5217(21) & -0.2166(35) & 0.0729(10) & 0.084(6)\end{array}$

Table 2. Anisotropic thermal parameters $\left(\AA^{2}\right)$ in the form $\exp \left[-2 \pi^{2}\left(h^{2} a^{-2} U_{11}+\cdots+2 h k a^{-1} b^{-1} U_{12}+\cdots\right)\right]$. All values have been multiplied by $10^{4}$. Standard deviations from the least squares refinement are given in parentheses.

Diselenocyanatobis(trimethylenethiourea)tellurium(II)

$\begin{array}{ccccccc} & U_{11} & U_{22} & U_{33} & U_{12} & U_{23} & U_{13} \\ \mathrm{Te} & \mathbf{5 5 4}(15) & \mathbf{3 5 1}(6) & \mathbf{3 8 7}(7) & 11(9) & -43(7) & 265(8) \\ \mathrm{Se} & \mathbf{5 2 3}(18) & 551(11) & 520(12) & 2(11) & -39(8) & 237(12) \\ \mathrm{S} & \mathbf{9 6 5 ( 5 0 )} & \mathbf{4 6 1 ( 2 2 )} & \mathbf{5 1 9 ( 2 6 )} & -\mathbf{6 ( 2 7 )} & 0(19) & 430(30)\end{array}$

Diselenocyanatobis(tetramethylthiourea)tellurium(II)

$\begin{array}{llllllc} & U_{11} & U_{22} & U_{33} & U_{12} & U_{23} & U_{13} \\ \mathrm{Te} & 570(7) & 532(12) & 486(6) & 86(9) & 32(9) & 135(5) \\ \mathrm{Se} & 756(12) & 671(18) & 815(13) & 82(11) & -38(12) & 158(10) \\ \mathrm{S} & \mathbf{4 9 2}(18) & 329(27) & 623(21) & 51(18) & 26(19) & 84(16)\end{array}$

Acta Chem. Scand. 25 (1971) No. 10 
Table 3. Observed and calculated structure factors $(\times 10)$ for trans-diselenocyanatobis(trimethylenethiourea)tellurium(II). Unobserved reflections are indicated by a minus sign on $F(O)$ and included at the threshold values. An asterisk denotes reflections given zero weight during the last refinement cycles.
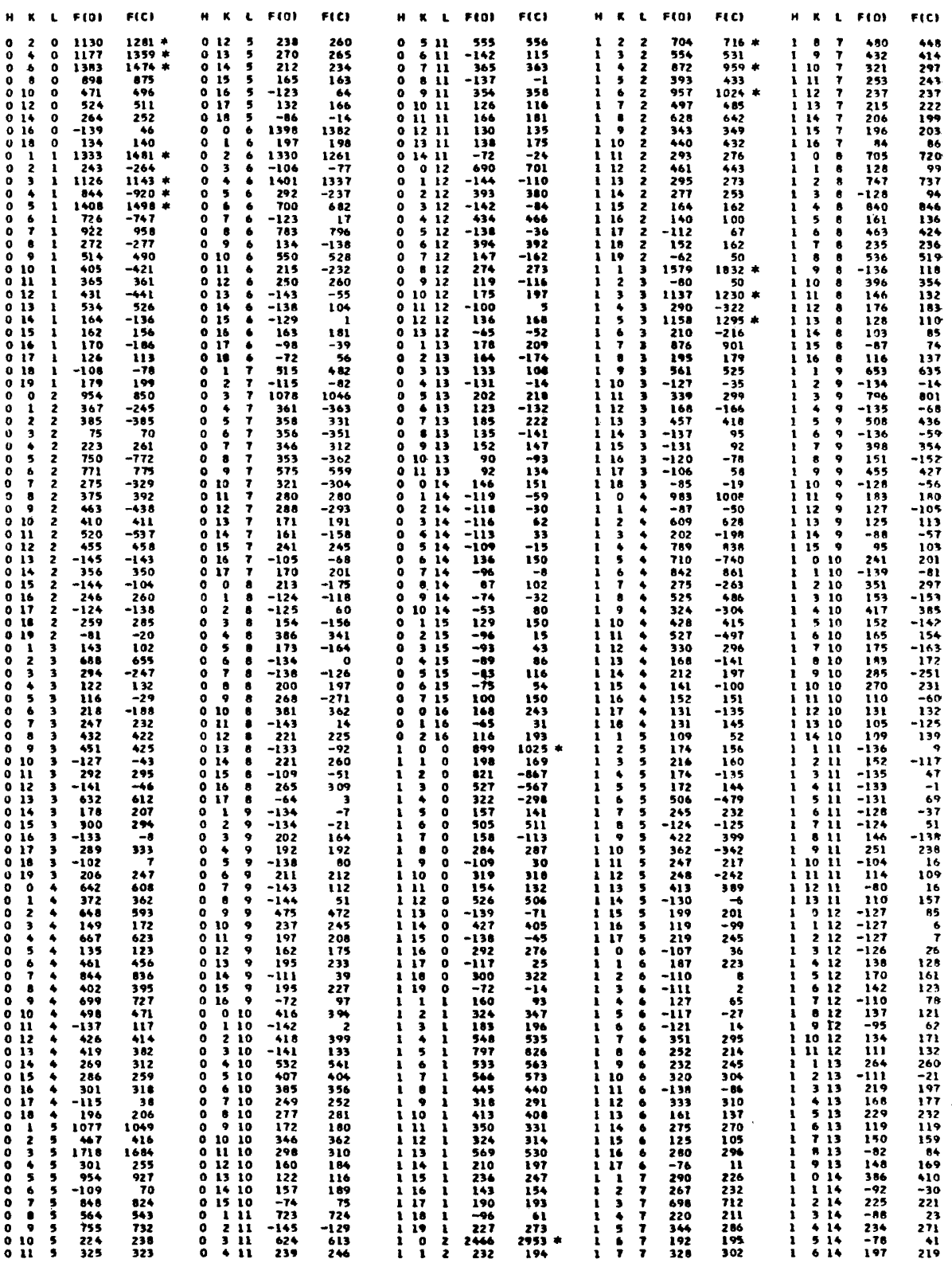

Acta Chem. Scand. 25 (1971) No. 10 
Table 3. Continued.

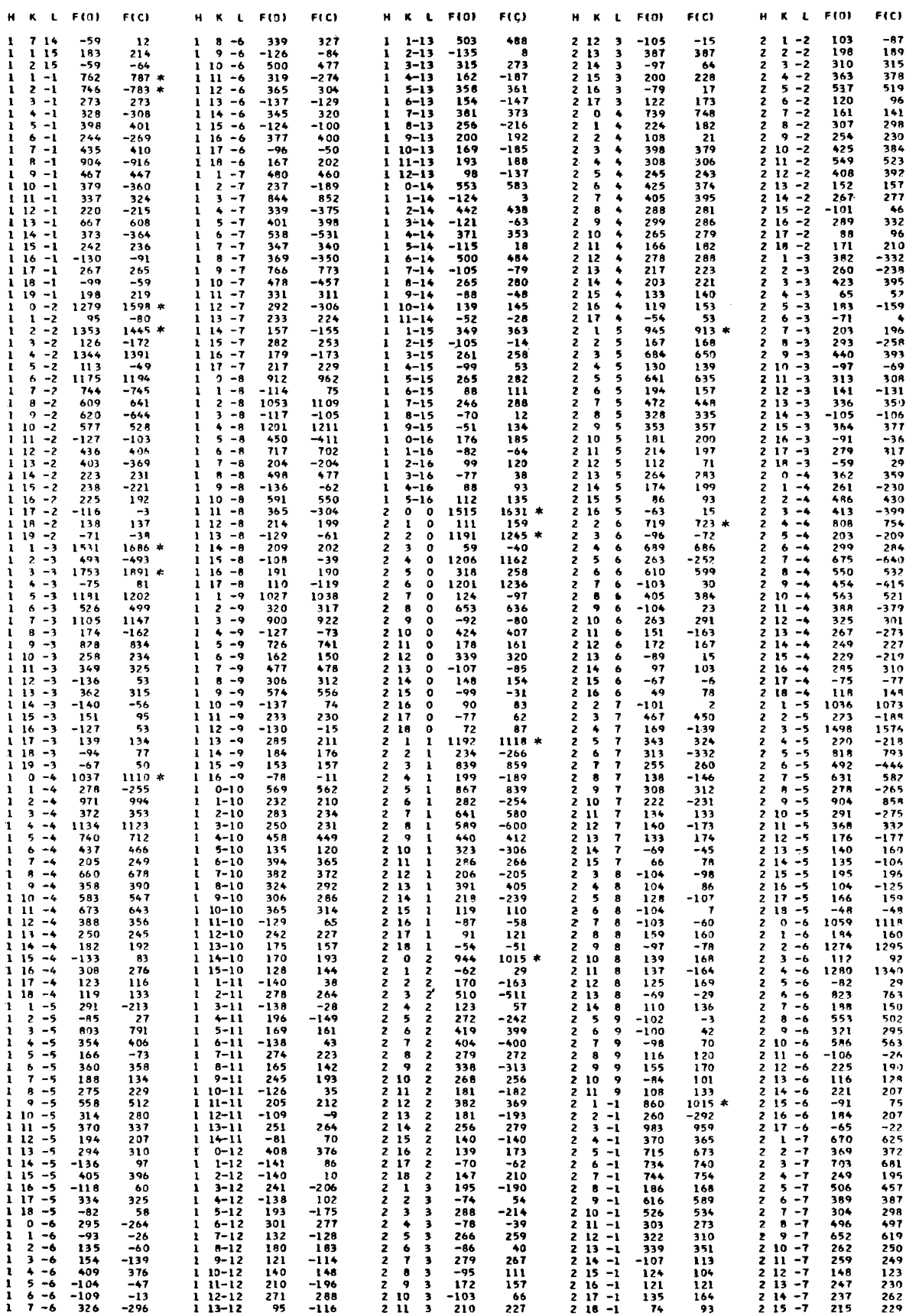

Acta Chem. Scand. 25 (1971) No. 10 
Table 3. Continued.

\begin{tabular}{|c|c|c|c|c|c|c|c|c|c|c|c|c|c|c|}
\hline K & $F(0)$ & $F$ & $\times 1$ & $F(0)$ & FIC & $\mathbf{H}$ & $F$ & $F(C)$ & $H$ & $F(0)$ & F(C) & $k$ & $F(n)$ & Fir) \\
\hline 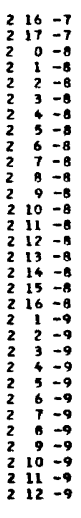 & 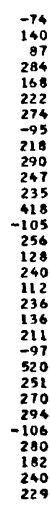 & 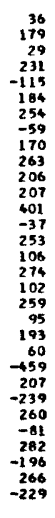 & $\begin{array}{ccc}2 & 13 & 13 \\
2 & 14 & -9 \\
2 & 15 & -9 \\
2 & 16 & -9 \\
2 & 0-10 \\
2 & 1-10 \\
2 & 2-10 \\
2 & 3-10 \\
2 & 4-10 \\
2 & 5-10 \\
2 & 6-10 \\
2 & 7-10 \\
2 & 0-10 \\
2 & 9-10 \\
2 & 10-10 \\
2 & 11-10 \\
2 & 12-10 \\
2 & 13-10 \\
2 & 19-10 \\
2 & 15-10 \\
2 & 1-11 \\
2 & 2-11 \\
2 & 3-11 \\
2 & 4-11 \\
2 & 5-11 \\
2 & 6-11 \\
2 & 7-11 \\
2 & 0-11 \\
2 & 0-11 \\
2 & 10-11 \\
2 & 11-11 \\
2 & 12-11\end{array}$ & $\begin{array}{l}300 \\
382 \\
251 \\
104 \\
969 \\
115 \\
425 \\
332 \\
516 \\
343 \\
533 \\
233 \\
331 \\
276 \\
283 \\
358 \\
317 \\
160 \\
202 \\
57 \\
917 \\
192 \\
665 \\
184 \\
667 \\
106 \\
612 \\
-1103 \\
311 \\
135 \\
237 \\
82\end{array}$ & 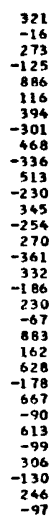 & 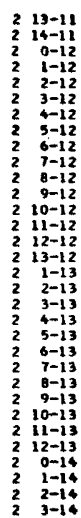 & 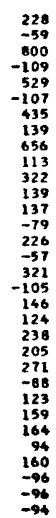 & $\begin{array}{c}282 \\
-38 \\
775 \\
100 \\
515 \\
-10 \\
114 \\
147 \\
648 \\
115 \\
341 \\
141 \\
164 \\
88 \\
261 \\
53 \\
311 \\
29 \\
128 \\
98 \\
227 \\
202 \\
306 \\
81 \\
119 \\
175 \\
165 \\
105 \\
157 \\
-60 \\
43 \\
13\end{array}$ & 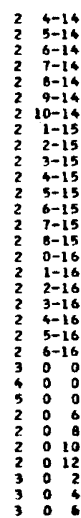 & 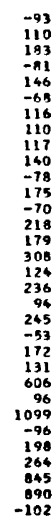 & 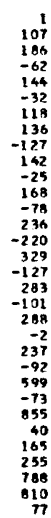 & 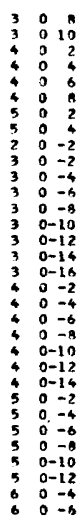 & $\begin{array}{l}417 \\
111 \\
109 \\
145 \\
368 \\
359 \\
157 \\
163 \\
107 \\
233 \\
979 \\
596 \\
123 \\
1399 \\
611 \\
293 \\
634 \\
90 \\
103 \\
266 \\
964 \\
163 \\
675 \\
521 \\
-55 \\
284 \\
234 \\
90 \\
397 \\
169 \\
75 \\
76 \\
132\end{array}$ & 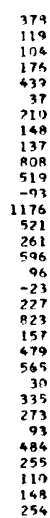 \\
\hline
\end{tabular}

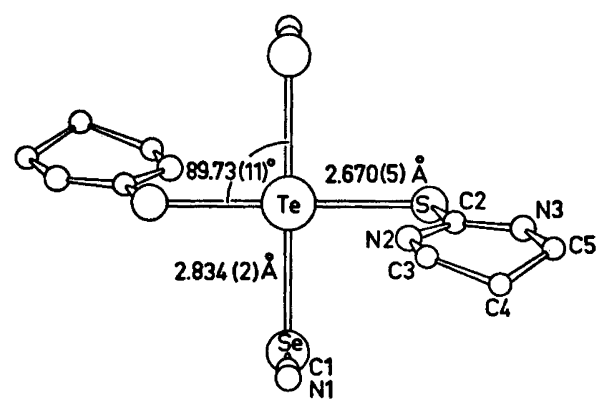

Fig. 1. The trans-diselenocyanatobis(trimethylenethiourea)tellurium(II) molecule as seen along the normal to the plane of the $\mathrm{TeSe}_{2} \mathrm{~S}_{\mathbf{2}}$ coordination group.

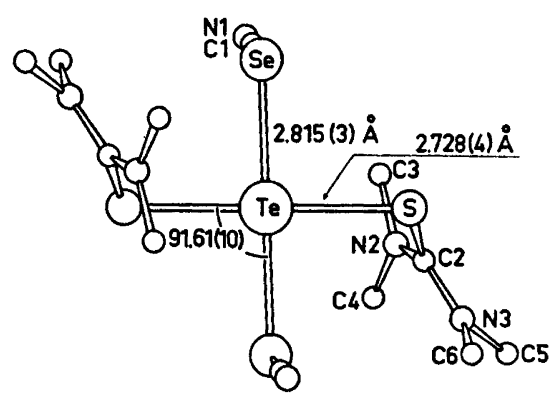

Fig. 2. The trans-diselenocyanatobis(tetramethylthiourea)tellurium(II) molecule as seen along the normal to the plane of the $\mathrm{TeSe}_{2} \mathrm{~S}_{2}$ coordination group.

Both compounds exhibit trans square-planar coordination, with the tellurium atom bonded to two selenium atoms and two sulphur atoms.

Including the present compounds, the crystal structures of four centrosymmetric, square-planar tellurium(II) complexes containing Te-Se bonds have been determined so far. Three are tellurium diselenocyanate complexes, $\mathrm{TeL}_{2}(\mathrm{SeCN})_{2}$, where $\mathrm{L}=$ ethylenethiourea, ${ }^{1}$ trimethylenethiourea, and tetramethylthiourea. Each of these yield one $\mathrm{Te}-\mathrm{Se}$ bond length. The fourth compound is tetrakis(selenourea)tellurium(II) dichloride, ${ }^{8} \mathrm{Te}(\mathrm{su})_{4} \mathrm{Gl}_{2}$, where $\mathrm{su}=$ selenourea. The latter yields two crystallographically independent $\mathrm{Te}-\mathrm{Se}$ bond lengths. The bond length data are summarized in Table 7, together with bond angles at tellurium and bond angles at selenium. The former angles are very close to $90^{\circ}$ in all compounds, and the latter angles range from $91.7^{\circ}$ to $100.9^{\circ}$. 
Table 4. Observed and calculated structure factors $(\times 10)$ for trans-diselenocyanatobis(tetramethylthiourea)tellurium(II). Unobserved reflections are indicated by a minus sign on $F(\mathrm{O})$ and included at the threshold values. An asterisk denotes reflections given zero weight during the last refinement cycles.
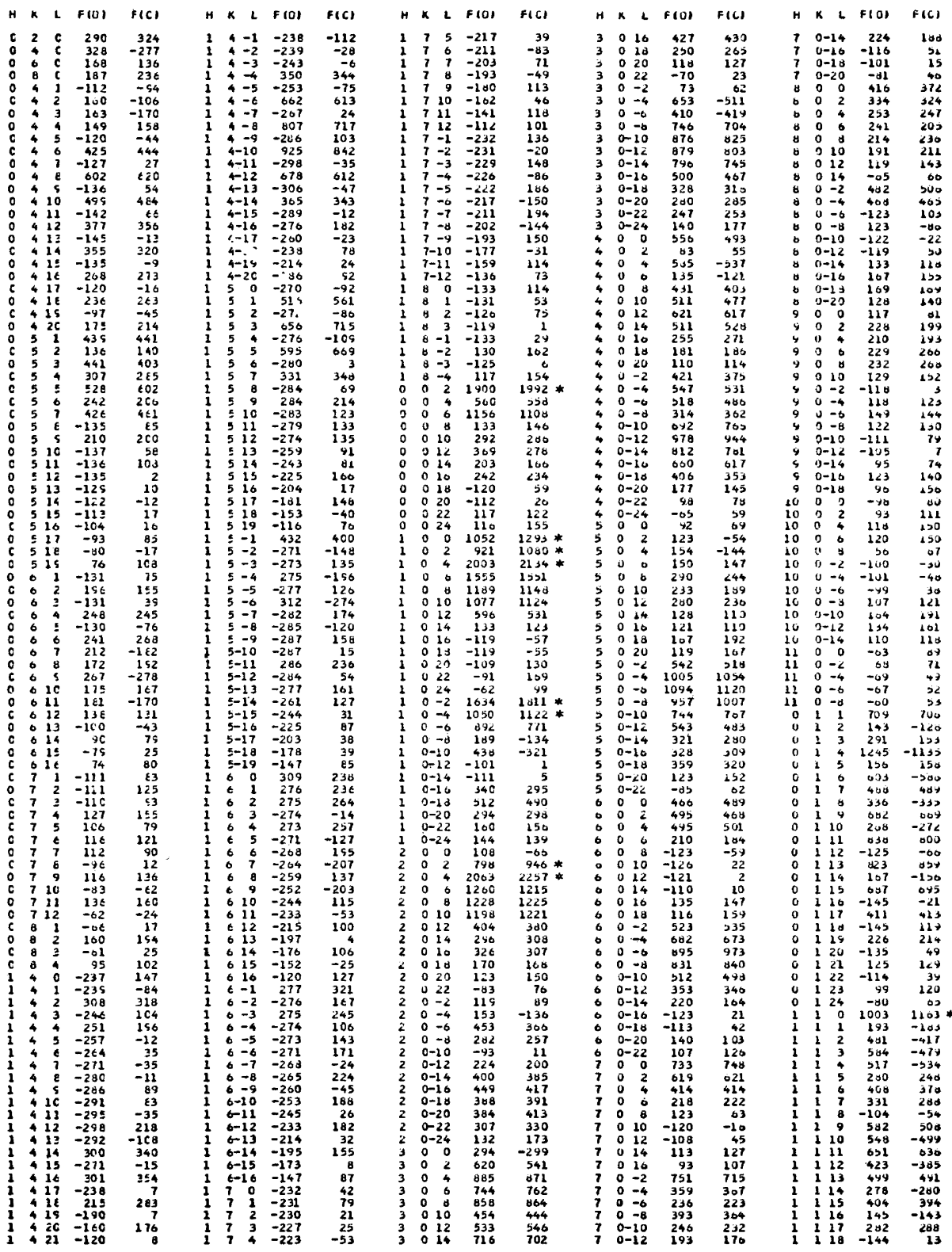

Acta Chem. Scand. 25 (1971). No. 10 
Table 4. Continued.

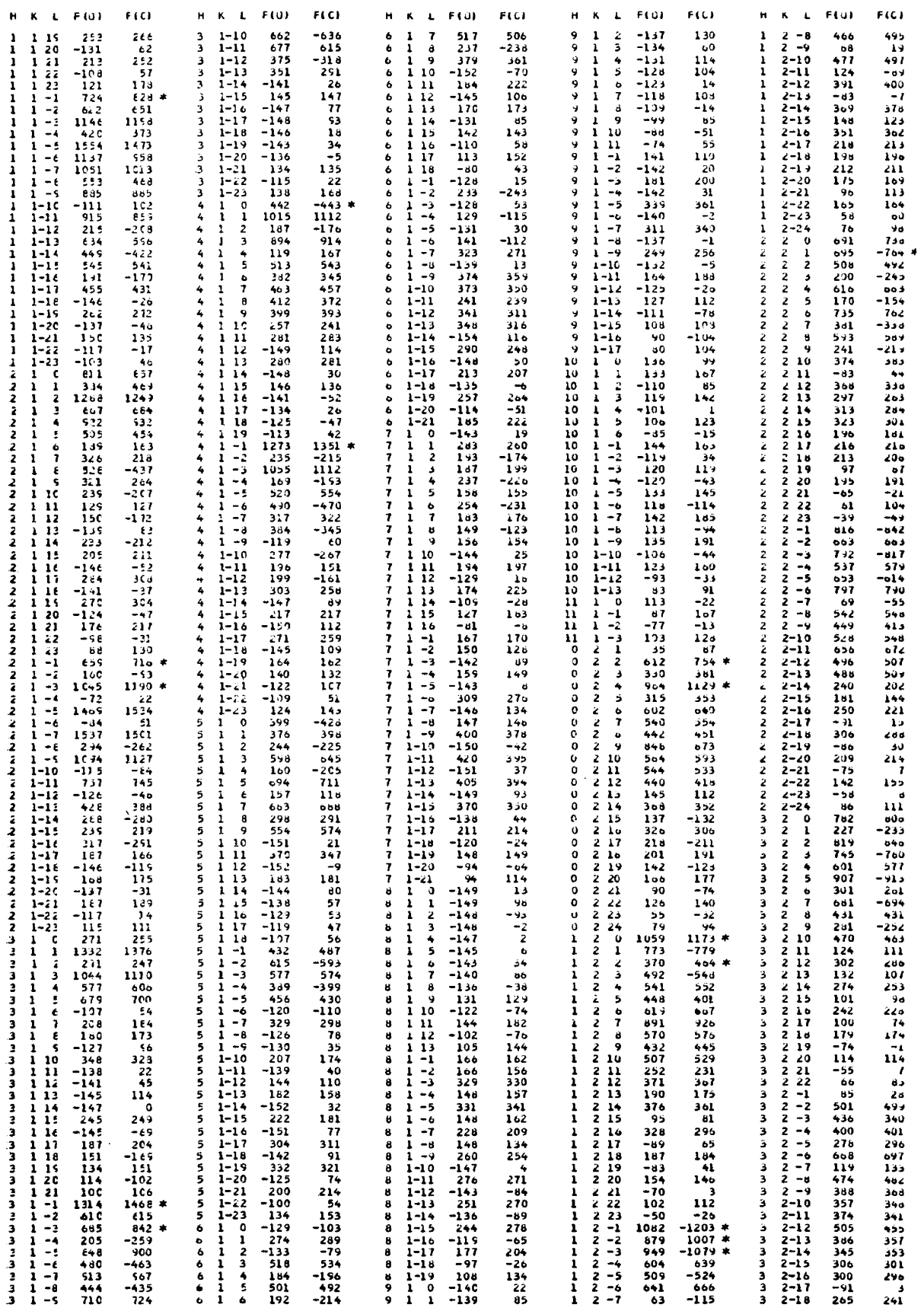

Acta Chem. Scand. 25 (1971) No. 10 
Table 4. Continued.

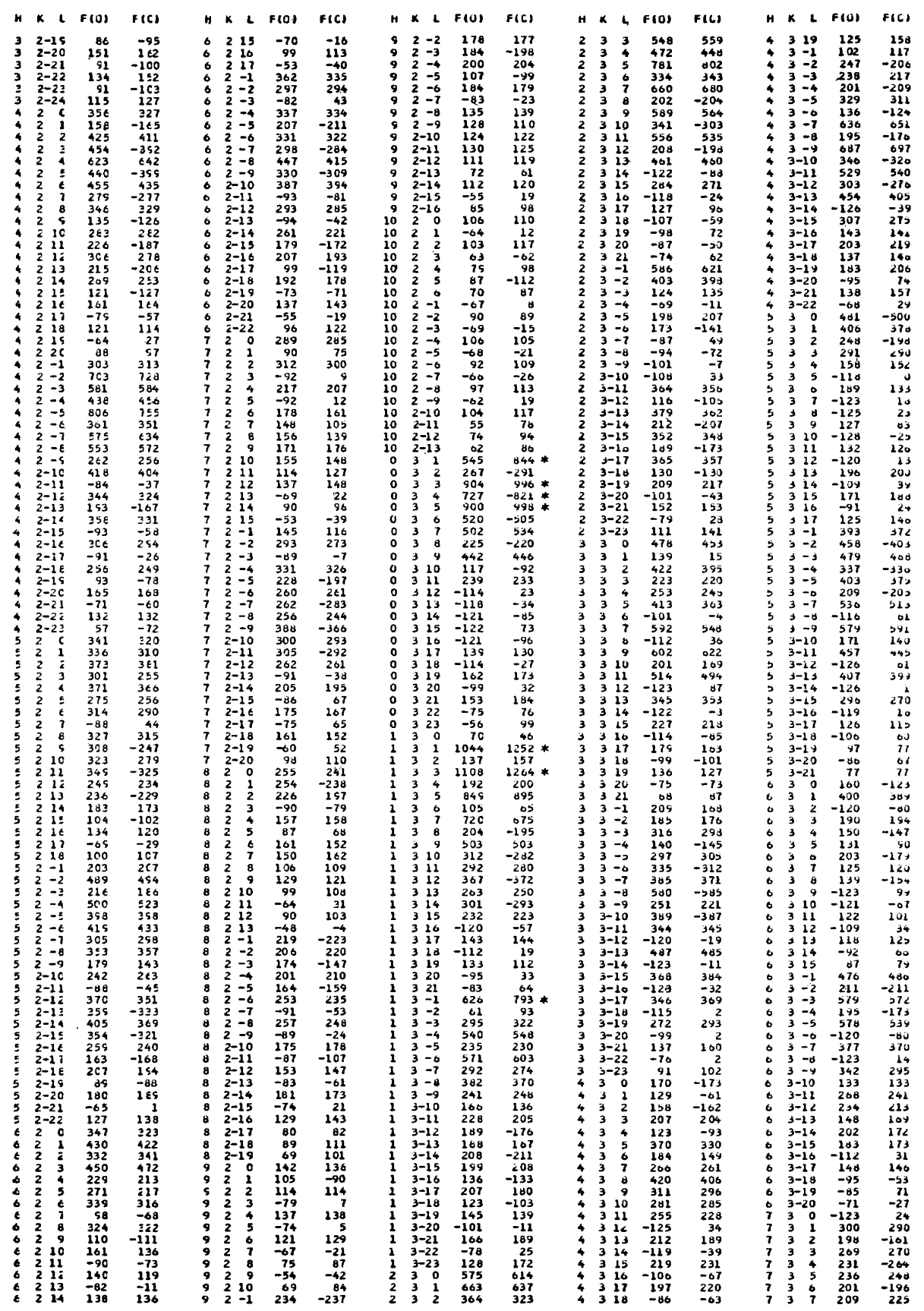

Acta Chem. Scand. 25 (1971) No. 10 
Table 4. Continued.

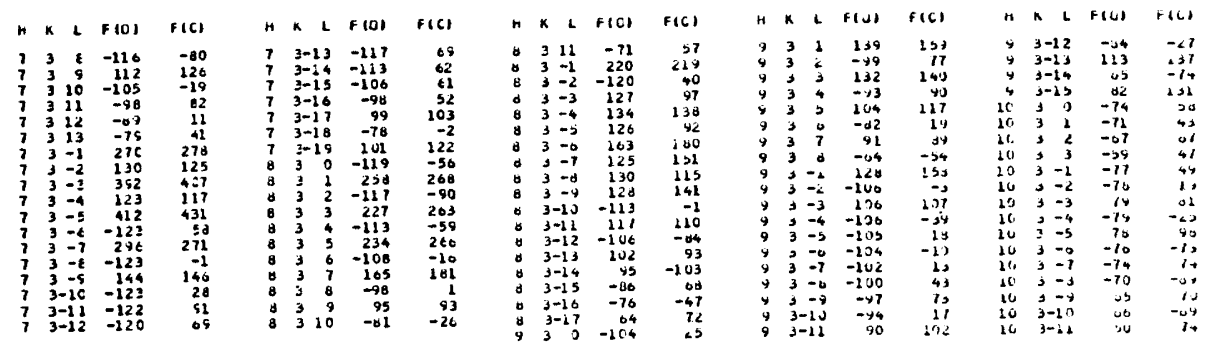

Table 5. Bond lengths $(\AA)$ and angles $\left(^{\circ}\right)$ in the coordination groups. Standard deviations are given in parentheses.

Trimethylenethiourea complex

$\mathrm{Te}-\mathrm{Se}$
$\mathrm{Te}-\mathrm{S}$
$\angle \mathrm{Se}-\mathrm{Te}-\mathrm{S}$
$\angle \mathrm{Te}-\mathrm{Se}-\mathrm{C}(1)$
$\angle \mathrm{Te}-\mathrm{S}-\mathrm{C}(2)$

$$
\begin{gathered}
2.834(2) \\
2.670(5) \\
89.73(11) \\
100.9(6) \\
106.2(6)
\end{gathered}
$$

Tetramethylthiourea complex

$$
\begin{array}{r}
2.815(3) \\
2.728(4) \\
91.61(10) \\
99.8(7) \\
98.9(6)
\end{array}
$$

Table 6. Bond lengths $(\AA)$ and angles $\left(^{\circ}\right)$ in the ligands. Standard deviations are given in parentheses.

Diselenocyanatobis(trimethylenethiourea)tellurium(II)

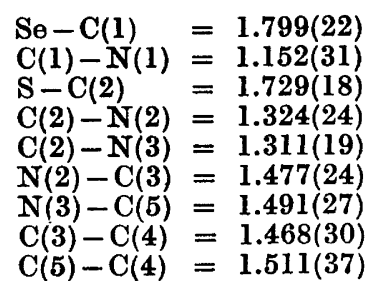

$$
\begin{array}{ll}
\angle \mathrm{Se}-\mathrm{C}(1)-\mathrm{N}(1) & =178.5(17) \\
\angle \mathrm{S}-\mathrm{C}(2)-\mathrm{N}(2) & =122.4(11) \\
\angle \mathrm{S}-\mathrm{C}(2)-\mathrm{N}(3) & =115.6(15) \\
\angle \mathrm{C}(2)-\mathrm{N}(2)-\mathrm{C}(3) & =124.8(13) \\
\angle \mathrm{C}(2)-\mathrm{N}(3)-\mathrm{C}(5) & =122.7(17) \\
\angle \mathrm{N}(2)-\mathrm{C}(3)-\mathrm{C}(4) & =110.3(19) \\
\angle \mathrm{N}(3)-\mathrm{C}(5)-\mathrm{C}(4) & =111.5(17) \\
\angle \mathrm{N}(2)-\mathrm{C}(2)-\mathrm{N}(3) & =121.5(16)
\end{array}
$$

Diselenocyanatobis(tetramethylthiourea)tellurium(II)

$$
\begin{aligned}
& \mathrm{Se}-\mathrm{C}(1)=1.809(20) \\
& \mathrm{C}(1)-\mathrm{N}(1)=1.162(27) \\
& \mathrm{S}-\mathrm{C}(2)=1.755(19) \\
& \mathrm{C}(2)-\mathrm{N}(2)=1.392(23) \\
& \mathrm{C}(2)-\mathrm{N}(3)=1.339(22) \\
& \mathrm{N}(2)-\mathrm{C}(3)=1.405(25) \\
& \mathrm{N}(2)-\mathrm{C}(4)=1.424(30) \\
& \mathrm{N}(3)-\mathrm{C}(5)=1.539(26) \\
& \mathrm{N}(3)-\mathrm{C}(6)=1.425(25)
\end{aligned}
$$

$$
\begin{aligned}
& \angle \mathrm{Se}-\mathrm{C}(1)-\mathrm{N}(1)=176.9(19) \\
& \angle \mathrm{S}-\mathrm{C}(2)-\mathrm{N}(2)=122.8(13) \\
& \angle \mathrm{S}-\mathrm{C}(2)-\mathrm{N}(3)=119.3(13) \\
& \angle \mathrm{N}(2)-\mathrm{C}(2)-\mathrm{N}(3)=117.9(16) \\
& \angle \mathrm{C}(2)-\mathrm{N}(2)-\mathrm{C}(3)=119.2(17) \\
& \angle \mathrm{C}(2)-\mathrm{N}(2)-\mathrm{C}(4)=122.8(16) \\
& \angle \mathrm{C}(3)-\mathrm{N}(2)-\mathrm{C}(4)=117.4(15) \\
& \angle \mathrm{C}(2)-\mathrm{N}(3)-\mathrm{C}(5)=126.2(15) \\
& \angle \mathrm{C}(2)-\mathrm{N}(3)-\mathrm{C}(6)=122.5(15) \\
& \angle \mathrm{C}(5)-\mathrm{N}(3)-\mathrm{C}(6)=111.0(15)
\end{aligned}
$$

Acta Chem. Scand. 25 (1971) No. 10 
Table 7. $\mathrm{Te}-\mathrm{Se}$ bond lengths in centrosymmetric, square-planar tellurium(II) complexes.

\begin{tabular}{llccc}
\hline \multicolumn{1}{c}{ Compound $^{a}$} & $\mathrm{Te}-\mathrm{Se}$ & $\angle \mathrm{X}-\mathrm{Te}-\mathrm{Se}^{b}$ & $\angle \mathrm{Te}-\mathrm{Se}-\mathrm{C}$ & Ref. \\
\hline $\mathrm{Te}(\mathrm{etu})_{2}(\mathrm{SeCN})_{2}$ & $2.809(3) \AA$ & $89.9(2)^{\circ}$ & $95.9(9)^{\circ}$ & \\
$\mathrm{Te}(\operatorname{trtu})_{2}(\mathrm{SeCN})_{2}$ & $2.834(2)$ & $89.7(1)^{\circ}$ & $100.9(6)^{\circ}$ & Present \\
$\mathrm{Te}(\operatorname{tmtu})_{2}(\mathrm{SeCN})_{2}$ & $2.815(3)$ & $91.6(1)^{\circ}$ & $99.8(7)^{\circ}$ & Present \\
$\mathrm{Te}(\mathrm{su})_{4} \mathrm{Cl}_{2}$ & $2.814(3)$ & $90.3(1)^{\circ}$ & $91.7(7)^{\circ}$ & 8 \\
& $2.809(4)$ & & $98.0(8)^{\circ}$ & 8 \\
\hline
\end{tabular}

$a$ etu $=$ ethylenethiourea, $\quad \operatorname{trtu}=$ trimethylenethiourea, $\quad \operatorname{tm} t u=$ tetramethylthiourea, $\quad \mathbf{s u}=$ selenourea.

${ }^{b}$ Or the supplementary angles.

Four of the five $\mathrm{Te}-\mathrm{Se}$ bond lengths, i.e., all except the length in $\mathrm{Te}(\mathrm{trtu})_{2}(\mathrm{SeCN})_{2}$, are equal within the error. The extremes of the four nearly equal lengths are 2.809(3) and 2.815(3) $\AA$; the difference between the extremes is 1.4 times the standard deviation of the difference. The weighted average of the four is $2.812(2) \AA$, with an average deviation of $0.003 \AA$. This length for a $\mathrm{Te}-\mathrm{Se}$ bond, $2.81 \AA$, is $0.13 \AA$ larger than the average $\mathrm{Te}-\mathrm{S}$ bond length, ${ }^{9} 2.68 \AA$, in centrosymmetric, square-planar tellurium(II) complexes. This is the same difference as between the covalent single-bond radii of the ligand atoms, $1.17 \AA$ for selenium and $1.04 \AA$ for sulphur.

The Te-Se bond length in $\mathrm{Te}(\operatorname{trtu})_{2}(\mathrm{SeCN})_{2}, 2.834(2) \AA$, is significantly larger than the other four. Also, the $\mathrm{Te}-\mathrm{S}$ bond length in $\mathrm{Te}(\mathrm{tmtu})_{2}(\mathrm{SeCN})_{2}$, $2.728(4) \AA$, is significantly larger than the average, $2.68 \AA$, for $\mathrm{Te}-\mathrm{S}$ bonds. The reasons are not clear; however, bond length variations like these do hardly appear surprising. The bonds are longer and weaker than covalent single bonds, and lattice effects, and ligand properties other than the nature of the coordinating atom, may be expected to influence their length.

In $\mathrm{Te}(\mathrm{tmtu})_{2}(\mathrm{SeCN})_{2}$ a non-bonded contact occurs between a tetramethylthiourea methyl group and the tellurium atom of the same molecule: $\mathrm{Te} \cdots \mathrm{C}(3)=3.732 \AA$, which is markedly shorter than the sum of the van der Waals radii ${ }^{10}$ of tellurium, $2.20 \AA$, and methyl, $2.00 \AA$. This contact is probably repulsive, and may relate to the observed lengthening of the Te-S(tmtu) bond.

Looking at $\mathrm{Te}-\mathrm{S}(\mathrm{tmtu})$ bond lengths in other centrosymmetric tellurium(II) complexes, the bond is $2.724(6) \AA$ in the dibenzenethiosulphonate complex, $\mathrm{Te}(\mathrm{tmtu})_{2}\left(\mathrm{~S}_{2} \mathrm{O}_{2} \mathrm{C}_{6} \mathrm{H}_{5}\right)_{2}$, but there the $\mathrm{S}-\mathrm{Te}-\mathrm{S}$ bond angle, 79.51(15) ${ }^{\circ}$, deviates markedly from $90^{\circ} .1$ The $\mathrm{Te}-\mathrm{S}$ (benzenethiosulphonate) bond is $2.657(4) \AA .^{11}$ In the cationic complexes, trans-dithioureabis(tetramethylthiourea)tellurium(II) chloride and bromide, $\left[\mathrm{Te}(\mathrm{tu})_{2}(\text { tmtu })_{2}\right] \mathrm{X}_{2}, \mathrm{Te}-\mathrm{S}($ tmtu $)=$ $2.688(3) \AA, \mathrm{Te}-\mathrm{S}(\mathrm{tu})=2.710(3) \AA, \angle \mathrm{S}-\mathrm{Te}-\mathrm{S}=91.37(10)^{\circ}$ in the chloride, and $\mathrm{Te}-\mathrm{S}(\mathrm{tmtu})=2.679(3) \AA, \mathrm{Te}-\mathrm{S}(\mathrm{tu})=2.706(3) \AA, \angle \mathrm{S}-\mathrm{Te}-\mathrm{S}=91.45(9)^{\circ}$ in the bromide. ${ }^{12}$

Bond lengths and angles in the ligands of the present complexes (Table 6) are in the normal range. With the sulphur coordinates given four times the weight of the carbon and nitrogen coordinates, and with $\mathrm{C}(4)$ excluded, a 
least-squares plane through the trimethylenethiourea group of $\mathrm{Te}(\operatorname{trtu})_{2}(\mathrm{SeCN})_{2}$ was calculated. The distances of the atoms from the plane range from 0.005 to $0.059 \AA$. The distance between $\mathrm{C}(4)$ and the plane is $0.482 \AA$. The angle between the least-squares plane and the plane through the $\mathrm{TeSe}_{2} \mathrm{~S}_{2}$ coordination group is $75.7^{\circ}$.

In calculations of least-squares planes through groups of atoms in $\mathrm{Te}(\mathrm{tmtu})_{2}(\mathrm{SeCN})_{2}$, the coordinates of all atoms were assigned equal weights. The atoms of a least-squares plane through the thiourea part of the tetramethylthiourea group deviate $0.003-0.009 \AA$ from the plane. This plane makes an angle of $77.3^{\circ}$ with the plane through the $\mathrm{TeSe}_{2} \mathrm{~S}_{2}$ coordination group, $29.9^{\circ}$ with a least-squares plane through $\mathrm{N}(2)$ and the carbon atoms bonded to $\mathrm{N}(2)$, and $25.7^{\circ}$ with a least-squares plane through $\mathrm{N}(3)$ and the carbon atoms bonded to $\mathrm{N}(3)$.

\section{A DIMORPH OF THE TRIMETHYLENETHIOUREA COMPLEX}

The dithiocyanato complex, $\mathrm{Te}(\text { trtu })_{2}(\mathrm{SCN})_{2}$, crystallizes in the space group $C 2 / c$ (No. 15) with four formula units per unit cell, and $a=13.27 \AA$, $b=14.43 \AA, c=9.76 \AA, \beta=108.5^{\circ} .^{2}$ On seeding the diselenocyanato reaction mixture with crystals of the dithiocyanato complex, the isomorphous diselenocyanato complex, $\mathrm{Te}(\mathrm{trtu})_{2}(\mathrm{SeCN})_{2}$, a dimorph of I, crystallized: $a=13.33 \AA$, $b=14.60 \AA, c=9.92 \AA, \beta=108.5^{\circ}$. As in the case of the dithiocyanato complex, ${ }^{2}$ the systematic absences, and weak $h k l$ reflections when $l$ is odd, indicate that the tellurium atoms lie in symmetry centres of the space group C2/c (No. 15). The crystals of both compounds occur as prisms $\{110\}$.

It was not possible, by seeding with crystals of $I$, to obtain isomorphous crystals of the dithiocyanato complex.

\section{REFERENCES}

1. Åse, K., Bøyum, K., Foss, O. and Marøy, K. Acta Chem. Scand. 25 (1971) 24.57.

2. Foss, O. and Marøy, K. Acta Chem. Scand. 15 (1961) 1945.

3. Foss, O. and Johannessen, W. Acta Chem. Scand. 15 (1961) 1941.

4. Foss, O. Unpublished work (1965).

5. International Tables for X-Ray Crystallography, Kynoch Press, Birmingham 1962, Vol. III, p. 122.

6. Busing, W. R. and Levy, A. H. Acta Cryst. 10 (1957) 180.

7. Cromer, D. T. Acta Cryst. 18 (1965) 17.

8. Hauge, S. and Tysseland, M. Acta Chem. Scand. 25 (1971) 3072.

9. Foss, O. In Andersen, P., Bastiansen, O. and Furberg, S. Selected Topics in Structure Chemistry, Universitetsforlaget, Oslo 1967, p. 145.

10. Pauling L. The Nature of the Chemical Bond, 3rd Ed., Cornell University Press, Ithaca, New York 1960.

11. Ase, K. and Roti, I. Acta Chem. Scand. To be published.

12. Anderson, O. P. Acta Chem. Scand. 25 (1971) 3593.

Received March 29, 1971. 